\title{
OPTIMAL HARVESTING TIME OF FARMED AQUATIC POPULATIONS WITH NONLINEAR SIZE-HETEROGENEOUS GROWTH
}

\author{
MARCELO E. ARANEDA \\ University Marista de Mérida, Periférico norte tablaje catastral 13941 Carretera \\ Mérida - Progreso. C.P. 97300 Merida, Yucatan, Mexico \\ E-mail: maraneda@marista.edu.mx \\ JUAN M. HERNÁNDEZ* \\ University of Las Palmas de Gran Canaria, Department of Quantitative Methods \\ in Economics. c/Saulo Torón s/n, 35017 Las Palmas, Spain \\ E-mail: jhernandez@dmc.ulpgc.es \\ EUCARIO GASCA-LEYVA \\ Centro de Investigación y de Estudios Avanzados (CINVESTAV), Unidad Mérida, \\ Carretera Mérida - Progreso Km.6, C.P. 97310, Merida, Yucatan, Mexico \\ E-mail: eucario@mda.cinvestav.mx
}

\begin{abstract}
This paper examines the question of optimal harvesting time in a size-heterogeneous farmed aquatic population, using a model reflecting the effect of population density on both overall mortality rate and individual growth. This analysis enables an optimal harvesting rule to be deduced. The results obtained are applied to shrimp culture in recirculation systems in Mexico. Numerical solutions are derived for different production scenarios. Assuming identical culture conditions, results are also obtained under the hypothesis of homogeneous population growth, the view traditionally taken in the relevant economic literature. The optimal harvesting times calculated tend to decrease with higher densities, although this rule fails under the size-heterogeneous population model. In general, optimal harvesting times are overestimated when size-homogeneity in the culture is assumed. Our analysis reveals that management predictions are significantly mistaken if the size-heterogeneity phenomenon is not taken into account.
\end{abstract}

KEY WORDS: Size-structured populations, optimal harvesting time, fish farming, shrimp, recirculation system.

\footnotetext{
*Corresponding author. Juan M. Hernández; University of Las Palmas de Gran Canaria, Department of Quantitative Methods in Economics. c/Saulo Torón s/n, 35017 Las Palmas, Spain, e-mail: jhernandez@dmc.ulpgc.es

Received by the editors on $25^{\text {th }}$ October 2010. Accepted $12^{\text {th }}$ July 2011.
} 
1. Introduction. Size heterogeneity is a common phenomenon in wild and farmed populations belonging to the same cohort. Differences in individual size have been extensively reported in both ecological (Pfister and Peacor [2003], Peacor and Pfister [2006], Peacor et al. [2007a]) and aquaculture research (Volpato and Fernandes [1994], Howell [1998], Kestemont et al. [2003], Moran [2007]). The origin of this variability is associated with a series of factors, such as genetic conditions, food limitation or social interactions in crowded environments (Brett [1979], Reed and Clarke [1990], Peacor et al. [2007b], Huss et al. [2007]). The high-density or intensive culture system currently developed in most industrialized countries reinforces size-variability among individuals. To give an example, several studies of shrimp culture have reported that high stocking densities increase the commanding position of large organisms over smaller ones for feeding, refuge and sexual partners, leading to higher levels of size heterogeneity (Harán et al. [2004], Arnold et al. [2006]).

The aim of this paper is to analyze the influence of size heterogeneity on the management of farmed aquatic populations, focusing in particular on the optimal harvesting time of the culture. Although this question has been extensively analyzed, most recommendations on harvesting time are made under the (nonrealistic) assumption of a homogeneous population. In this paper, a nonlinear continuous size-structured model was assumed, in order to represent size-variability in the population, where individual growth is assumed to be density-dependent. By including the size-heterogeneity phenomenon and density-dependent growth in the economic analysis, the management recommendations derived are more appropriate to real-world situations.

The use of size-structured models in aquaculture may also help in designing the marketing strategies to be recommended. In general, the market assigns different values to a given species depending on its size or presentation, and thus there co-exist several groups or classes. The farmer may decide the production pattern to be addressed for each class in order to focus on specific market segments. Size-structured models enable a better estimation to be made of the amount of each class to be produced in the culture cycle. Thus, managers can anticipate the quantity of individuals belonging to each class and therefore decide on the best strategy to use to allocate the product in the market. This 
approach is not possible with the traditional models that assume size homogeneity.

The rest of the paper is organized as follows. Section 2 reviews the literature on optimal harvesting rules in fish culture. Section 3 presents two models of fish growth, assuming size-homogeneous and size-heterogeneous populations, respectively. The theoretical calculations of the optimal harvesting time for both cases are detailed in Section 4. An empirical application of the analytical results to intensive shrimp culture in Mexico is presented in Section 5, where the economic returns predicted by both models are compared. Finally, Section 6 discusses the results obtained and the relevant conclusions are drawn.

2. Optimal harvesting in fish culture. ${ }^{1}$ Many studies have reported analytical results regarding the question of optimal harvesting in fish culture. A significant proportion of these studies have focused on determining the most profitable harvesting time of a culture cycle, taking into account the influence of discount rates, feed purchases and other costs (Bjorndal [1988], Hean [1994]) or the scale of prices (Mistiaen and Strand [1999]). These results are complemented by analyses of the optimal feed schedule during the culture (Arnason [1992], Hernández et al. [2007]), gradual culling (Heaps [1995]) and the influence of certain exogenous factors such as environmental protection measures (León-Santana and Hernández [2008]) or climate change (Lorenzen [2008]).

The above contributions are based on fish growth models which assume a homogeneous size for all individuals in the population. One reason for avoiding size-heterogeneity in optimal management studies is the obvious increase in complexity in formulating the model. However, some exceptions can be found in the literature, such as $\mathrm{Yu}$ and Leung [2005], who analyzed the optimal harvesting schedule in a multipond and multicycle discrete model during a fixed operation period. Size variability was exogenously introduced by these authors, using a size distribution function applied at the end of every cycle. Previously, Summerfelt et al. [1993] presented an aquaculture management model that included increasing size-variability among individuals with respect to fish weight. These authors simulated the harvested biomass 
obtained under certain management and economic scenarios. Subsequently, Forsberg [1996, 1999] used a discrete size-structured model including stochastic factors to find the most profitable harvest and stocking plan during a predetermined culture time. In both contributions, the problem is stated in the context of a multiperiod linear programming model in which linear growth dynamics is assumed. However, logistic-type growth is the most common pattern followed by fish or crustaceans in aquaculture farms. As observed by Forsberg [1999], linear fish growth is clearly unrealistic, even when necessary to numerically solve the problem.

As noted above, the size-structured models built to represent the variability of sizes in aquaculture farms usually assume discrete time. By doing so, the optimization problem can be solved using traditional numerical methods, such as linear programming. Nevertheless, the alternative continuous size-structured models present also some advantages. In particular, they allow us to obtain analytical results for the optimization problem, thus extending the classical formulas obtained with the simplistic size-homogeneous case (Bjorndal [1988]). Continuous size-structured models were first proposed by Sinko and Streifer [1967] and include a Partial Differential Equation (PDE) for the total number of individuals of every size at any time, where instantaneous individual growth depends on the interactions among all the individuals. Several extensions to this model have also been proposed, for example, Ackleh et al. [2004] and Kato et al. [2007]. Moreover, the numerical solution has been further developed by Angulo and López-Marcos [1999, 2004] and Kostova [2002].

In order to obtain analytical results for the optimal harvesting time problem, this paper presents a continuous size-structured model for population growth in aquaculture farms. To better represent the conditions in intensive cultures, individual growth is assumed to be nonlinear and density-dependent. The optimal harvesting time for one culture cycle is obtained theoretically and an application to intensive shrimp culture in Yucatan, Mexico, is then presented. The results obtained are compared with those derived when homogeneous fish growth is assumed. Similar comparisons have been carried out regarding the optimal management of fisheries (Moxnes [2005], Tahvonen [2008, 2009]). In these papers, the most profitable dynamic harvesting strategy was analyzed assuming an age-structured population, which was compared 
with the recommendations obtained using a homogeneous or "biomass" model. The results showed that the steady state of the biomass is lower if the biomass model is utilized in the predictions, while the optimal harvesting solutions derived using the age-structured model may present nonmonotonous paths, such as limit cycles or pulse fishing, which are not usually presented with size-homogeneous models. In the context of aquaculture farms, analytical results for optimal harvesting time with a simple linear size-heterogeneous model was calculated by Gasca-Leyva et al. [2008], whose results indicated that the farmer should keep the fish longer in culture if size-heterogeneity is taken into account. This paper extends the above findings to the more realistic case of a nonlinear model, in which both growth and mortality rates are dependent on the total number of individuals.

3. The biological models. This paper includes two models to represent the growth of biological actives (e.g., forest, fish, or livestock), although for notational convenience, the text refers solely to fish culture. The first model assumes that all organisms present an identical weight and growth pattern throughout the culture span. This condition ignores the existence of size (weight) variability in the same cage or pond. Hence, the population can be represented by a single individual, from the initial stocking to the harvesting time. This, indeed, has been the most common way of modeling fish growth in aquaculture. ${ }^{2}$ Given the size of the representative at time $t, x(t)$, growth is defined in the following differential equation:

$$
\dot{x}=g(x, \bar{N}), x\left(t_{0}\right)=x_{0},
$$

where $\bar{N}(t)$ indicates the total number of individuals at time $t, t_{0}$ and $x_{0}$ are the initial time and stocking size, respectively. Thus, fish growth depends not only on the fish size, but also on the density in the pond or cage. Function $g$ is assumed to be continuously differentiable on $[0, \omega] \times[0,+\infty)$ with $g(\omega, \bar{N})=0, \forall \bar{N}>0$, where $\omega$ is the maximum size a fish can reach $(\omega<\infty)$. The dependence on size is normally quadratic-shaped, that is, it describes a concave function with a unique maximum in the interval $(0, \omega)$. In general, a negative relationship between density and growth is expected in absolute and size-relative terms $\left.g_{\bar{N}}<0,(g / x)_{\bar{N}}<0\right)$. Some previous theoretical and empirical 
models have included this factor in fish growth (Hean [1994], Heaps [1995], Lorenzen [1996]).

The mortality rate of individuals, $\mu(\bar{N})$, is assumed to be nonnegative, bounded, continuously differentiable and positively dependent on the population density $\mu_{\bar{N}}>0$. Thus, the total number of individuals evolves in accordance with the expression

$$
\dot{\bar{N}}=-\mu(\bar{N}) \bar{N}, \bar{N}\left(t_{0}\right)=\bar{N}_{0},
$$

where $\bar{N}_{0}$ is the number of individuals at time $t=t_{0}$. The system $(\mathrm{h})=$ $(1) \cup(2)$ defines the dynamics of fish size and the number of individuals jointly, and is termed a size-homogeneous model or system (h).

The second model relaxes the hypothesis of identical growth and weight of individuals. Accordingly, at any time different sizes are present in the culture and it is not possible to single out a representative fish. It is assumed that the total number of individuals at the initial time $t=t_{0}$ follows a (probabilistic) density function in the interval of possible sizes, $\nu_{0}(x), x \in[0, \omega]$. Following the size-structured model presented by Sinko and Streifer [1967], the number of individuals at time $t$ with size $x, N(t, x)$, obeys the nonlinear partial differential equation

$$
\begin{aligned}
& N_{t}(t, x)+(g(x, \bar{N}) N(t, x))_{x}=-\mu(\bar{N}) N(t, x), 0<x<\omega, t>t_{0}, \\
\text { (3) } & N\left(t_{0}, x\right)=\bar{N}_{0} \nu_{0}(x), \\
& N(t, 0)=0 .
\end{aligned}
$$

The latter equation in (3) indicates that there is no reproduction or replacement of individuals in the lifetime of the culture. The mortality rate is identical to the size-homogeneous model and every individual follows the same growth pattern described in equation (1). The total number of individuals is

$$
\bar{N}(t)=\int_{0}^{\omega} N(t, x) d x .
$$

The system $(\mathrm{H})=(1) \cup(3)$ is an extension of system $(\mathrm{h})$, in which an initial distribution size $N\left(t_{0}, x\right)$ is assumed. Equation (2) is obtained by 
integrating equation (3) with respect to size $x$ (the proof for this is given in the Appendix). This second model is called the size-heterogeneous model or system $(H)$. A formal definition of the solution of system $(\mathrm{H})$, together with existence and uniqueness results, has been stated by Calsina and Saldaña [1995]. Recently, Veliov [2008] has extended these results to a broader context of dynamic optimization. The Appendix section presents the analytical conditions for the functions to ensure the existence and uniqueness of solutions to system $(\mathrm{H})$.

System $(\mathrm{H})$ assumes that only the initial distribution $\nu_{0}(x)$, the mortality rate and the total number of individuals determine the future distribution of sizes over time. The weight of some individuals does not influence mortality or the growth of other sizes. However, this is not the case for real populations. Size variability is dependent on the size distribution not only at the beginning of the culture, but also at certain periods afterward. Specifically, larger fish normally grow faster in the initial stages of the lifecycle. This phenomenon is called growth depensation and is related to dominance effects and the hierarchy ranging from the bigger individuals to the smaller ones in high-density environments (Kjartansson et al. [1988], Gadagkar [1997], Haran et al. [2004], Arnold et al. [2006], Gurney et al. [2007]). However, competition and negative social interaction can decrease after some time and a stage of growth stabilization can then follow. This is due to the appearance of new dominant organisms and the stabilization of social hierarchies, which leads to individuals' growth showing similar patterns, independent of their size (Barbosa et al. [2006], Peacor et al. [2007b]). Figure 1 illustrates the two stages of fish growth in accordance with these empirical findings. Growth depensation spans from the beginning of the culture to time $t=t_{0}$. Following this time, size-heterogeneity is stabilized and system $(\mathrm{H})$ can validly explain the population dynamics.

To test the growth pattern described in Figure 1 in a real culture, the relationship between the Coefficient of Variation $(C V(t))$ of fish sizes and the growth rate was examined. Given $\bar{x}(t)$ the mean size of individuals at time $t$ obtained from real data, $C V(t)$ is defined by the quotient between the standard deviation of sizes at time $t, \sigma_{\bar{x}}(t)$, and the mean size, that is, $C V(t)=\sigma_{\bar{x}}(t) / \bar{x}(t)$. Thus, this coefficient indicates the size dispersion in percentage terms for every fish size. If the growth pattern of individuals in the cage or pond follows the 


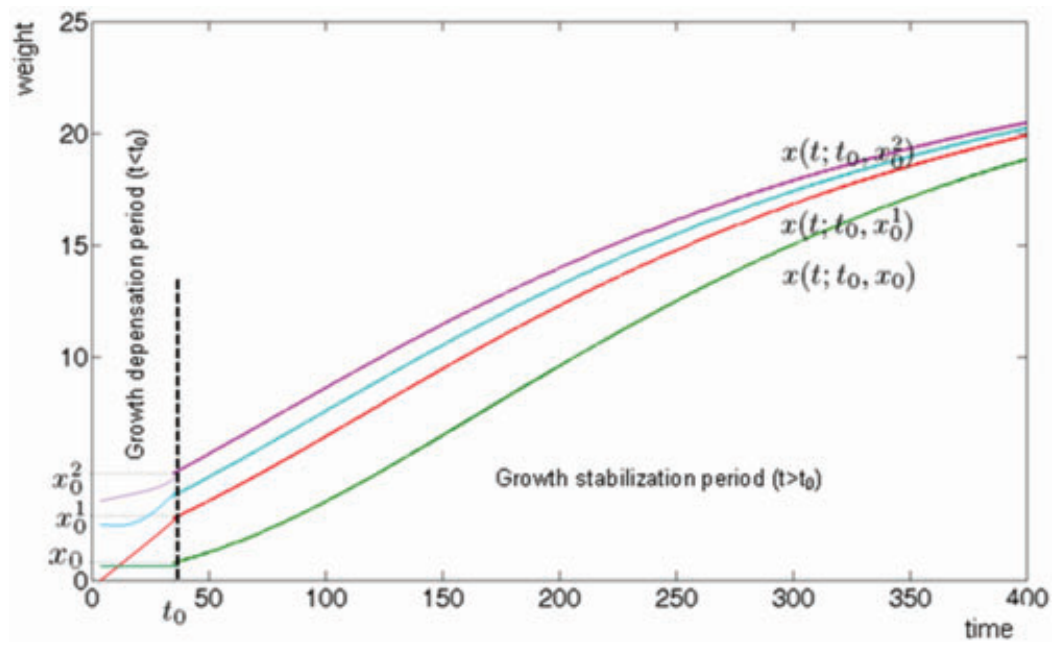

FIGURE 1. Growth depensation $\left(t<t_{0}\right)$ and stabilization period $\left(t>t_{0}\right)$ in high-density populations.

linear version of equation (3), that is, $g(x, \bar{N})=g(x)$ and $\mu(\bar{N})=\mu>$ 0 , the "relative size variation will change in proportion to the relative change in the per unit size growth rate" (Peacor et al. [2007a]). In mathematical terms, this assertion means

$$
\frac{C V(t)}{C V\left(t_{0}\right)} \cong \frac{g(\bar{x}) / \bar{x}}{g\left(\bar{x}_{0}\right) / \overline{x_{0}}}
$$

Equation (4) was proven by Peacor et al. [2007a], with the assumption that the mortality rate is zero. This equation holds if a nonlinear mortality rate $\mu(\bar{N})$ is assumed, but the relationship is not assured if the growth function is density-dependent. Nevertheless, equation (4) will be used to obtain an indication of the fitness of the empirical data to the size-structured model. Both sides of the equation can be estimated from the data and, if statistically similar values in the culture period at a given time $t_{0}$ are adopted, the size-structured model (3) with linear $g$ can be accepted. The nonlinear version is tested by validation. 
4. Analytical results. In this section, theoretical results for the optimal harvesting time, assuming models $(\mathrm{h})$ and $(\mathrm{H})$, are derived. The results obtained are extensions of those presented in Bjorndal [1988].

Optimal management is dependent on the structure of revenues and costs in the farm. In these models, a positive relationship between fish price and size is assumed, that is, larger sizes are more highly valued by the market. Function $p(x)$ represents the price per gram of a fish with size $x\left(p^{\prime}(x)>0\right)$. Additionally, farms incur an operation cost per individual during the culture span. This cost, $C(x, \bar{N})$, includes feeding and energy costs, which are dependent on fish size and density in the cage. It is assumed that the cost per individual decreases with density, that is, $C_{\bar{N}}<0$.

For simplicity, a single culture cycle is considered. The evaluation of the economic conditions also depends on the specific model. For the size-homogeneous model, the accumulated costs are given by

$$
C_{h}(t)=\int_{t_{0}}^{t} e^{-r \tau} C(x(\tau), \bar{N}(\tau)) \bar{N}(\tau) d \tau
$$

where parameter $r$ represents the discount rate in the economy. Therefore, the farmer's problem is to determine the harvesting time $t^{h}$ at which the present value of the net revenue obtained by harvesting all the biomass is maximal, that is,

$$
\operatorname{Max}_{t>t_{0}}, \pi=p(x(t)) x(t) \bar{N}(t) e^{-r t}-\int_{t_{0}}^{t} e^{-r \tau} C(x(\tau), \bar{N}(\tau)) \bar{N}(\tau) d \tau .
$$

The first-order condition for the solution of this problem is obtained by differentiating with respect to time the expression on the right-hand side and equating to zero. After some calculation and simplifications, it can be deduced that the optimal harvesting time necessarily satisfies the equation

$$
\begin{array}{r}
p^{\prime}\left(x\left(t^{h}\right)\right) g\left(x\left(t^{h}\right), \bar{N}\left(t^{h}\right)\right) x\left(t^{h}\right)+p\left(x\left(t^{h}\right)\right) g\left(x\left(t^{h}\right), \bar{N}\left(t^{h}\right)\right) \\
\quad=\left(r+\mu\left(\bar{N}\left(t^{h}\right)\right)\right) p\left(x\left(t^{h}\right)\right) x\left(t^{h}\right)+C\left(x\left(t^{h}\right), \bar{N}\left(t^{h}\right)\right) .
\end{array}
$$


Dividing the two terms by the individual market value, $(p(x) x)$, it follows that

$$
\begin{aligned}
\frac{p^{\prime}\left(x\left(t^{h}\right)\right)}{p\left(x\left(t^{h}\right)\right)} g\left(x\left(t^{h}\right), \bar{N}\left(t^{h}\right)\right) & +\frac{g\left(x\left(t^{h}\right), \bar{N}\left(t^{h}\right)\right)}{x\left(t^{h}\right)}=\left(r+\mu\left(\bar{N}\left(t^{h}\right)\right)\right) \\
& +\frac{C\left(x\left(t^{h}\right), \bar{N}\left(t^{h}\right)\right)}{p\left(x\left(t^{h}\right)\right) x\left(t^{h}\right)}
\end{aligned}
$$

which is a simple extension of the results presented in Bjorndal [1988]. The left-hand side of the expression represents the marginal revenue obtained by leaving the fish growing in the cage for one day more than $t^{h}$, while the right-hand side represents the marginal cost incurred thereby. From this equation alone, the effect of increasing culture densities on the optimal harvesting time is unclear due to diverse and contrary effects. On the one hand, an increase in the culture density would produce a decrease in the marginal revenue, since fish growth in both relative and absolute terms would be inhibited $\left(g_{\bar{N}}<0,(g / x)_{\bar{N}}<0\right)$. On the other hand, the direction of change in the marginal cost is not apparent, since the mortality rate would increase and individual operation costs would decrease when culture density is increased. Therefore, the net effect on the optimal harvesting time will depend on the particular functions empirically estimated.

The same argument made by Gasca-Leyva et al. [2008] reveals the existence of a maximum among the possible solutions of (6). Let us denote the difference between the left and the right-hand sides of equation (6) in time $t$ by $\xi(t)$. At the beginning of the culture, growth rates are usually low and costs high, due to the presence of fixed costs, and so $\xi\left(t_{0}\right)<0$. For $t>>t_{0}$, the fish weight reaches values close to $\omega$, and so $\xi(t)<0$ again, since $g(\omega, \bar{N})=0$. It is assumed that the concavity of function $g(., \bar{N})$ determines the shape of function $\xi(t)$ (and this is so in the empirical application), which thereby increases from negative to positive values for small $t$ and decreases to negative ones when $x(t)$ approaches $\omega$. Therefore, function $\pi$ achieves a local minimum for low values of $t$ (and $x$ ), and then a local maximum at a certain time $t^{h}$. This local maximum is global if $\pi\left(t^{h}\right)>\pi\left(t_{0}\right)$. In other case, the commercial activity is unprofitable. 
For the size-heterogeneous model, the accumulated operational cost at time $t$ is given by the formula

$$
C_{H}(t)=\int_{t_{0}}^{t} e^{-r \tau} \int_{0}^{\omega} C(x, \bar{N}(\tau)) N(\tau, x) d x d \tau
$$

The revenue at time $t$ is given by

$$
R_{H}(t)=e^{-r t} \int_{0}^{\omega} p(x) x N(t, x) d x
$$

which is only evaluated at the harvesting time. The farmer's problem is again to determine the harvesting time $t^{H}$ at which the net revenue $\Pi=R_{H}(t)-C_{H}(t)$ is maximal. By applying the first-order condition to $\Pi$ and using equation (3), the following equation is obtained,

$$
\int_{0}^{\omega} p(x) x N_{t}\left(t^{H}, x\right) d x-\int_{0}^{\omega}\left(r p(x) x+C\left(x, \bar{N}\left(t^{H}\right)\right)\right) N\left(t^{H}, x\right) d x=0
$$

Using equation (3), the first term in the previous equation is transformed into

$$
\begin{gathered}
\int_{0}^{\omega} p(x) x N_{t}\left(t^{H}, x\right) d x=-\int_{0}^{\omega} \mu\left(\bar{N}\left(t^{H}\right)\right) p(x) x N\left(t^{H}, x\right) d x \\
-\int_{0}^{\omega} p(x) x\left(g\left(x, \bar{N}\left(t^{H}\right)\right) N\left(t^{H}, x\right)\right)_{x} d x .
\end{gathered}
$$

After integrating the last term above by parts and observing that $g(\omega, \bar{N}(t))=0$, it follows that

$$
\begin{aligned}
\int_{0}^{\omega} p(x) x N_{t}\left(t^{H}, x\right) d x= & -\int_{0}^{\omega} \mu\left(\bar{N}\left(t^{H}\right)\right) p(x) x N\left(t^{H}, x\right) d x+\int_{0}^{\omega}\left(p^{\prime}(x) x\right. \\
& +p(x)) g\left(x, \bar{N}\left(t^{H}\right)\right) N\left(t^{H}, x\right) d x .
\end{aligned}
$$


Therefore, equation (7) can be written as,

$$
\begin{gathered}
\int_{0}^{\omega}\left[\left(p^{\prime}(x) x+p(x)\right) g\left(x, \bar{N}\left(t^{H}\right)\right)-\left(r+\mu\left(\bar{N}\left(t^{H}\right)\right)\right) p(x) x\right. \\
\left.-C\left(x, \bar{N}\left(t^{H}\right)\right)\right] N\left(t^{H}, x\right) d x=0 .
\end{gathered}
$$

This condition is an extension of equation (5), assuming heterogeneous sizes in the culture. In order to find $t^{H}$, it is first necessary to integrate equation (3). A more direct condition can be obtained by simplifying equation (8). Let us name $x\left(t ; t_{0}, x_{0}\right)$ or characteristic curve in $\left(t_{0}, x_{0}\right)$ the solution of the growth equation $(1) .{ }^{3}$ By performing the change of variable $x=x\left(t ; t_{0}, x_{0}\right), d x=\partial x\left(t ; t_{0}, x_{0}\right) / \partial x_{0} d x_{0}$ in equation (8) and applying the general solution of (3) and Lemma 1 presented in the Appendix, it follows that

$$
\begin{aligned}
\int_{0}^{\omega} & {\left[\left(p^{\prime}\left(x\left(t^{H} ; t_{0}, x_{0}\right)\right) x\left(t^{H} ; t_{0} x_{0}\right)+p\left(x\left(t^{H} ; t_{0}, x_{0}\right)\right)\right)\right.} \\
& \times g\left(x\left(t^{H} ; t_{0}, x_{0}\right), \bar{N}\left(t^{H}\right)\right) \\
& -\left(r+\mu\left(\bar{N}\left(t^{H}\right)\right)\right) p\left(x\left(t^{H} ; t_{0}, x_{0}\right)\right) x\left(t^{H} ; t_{0}, x_{0}\right) \\
& \left.-C\left(x\left(t^{H} ; t_{0}, x_{0}\right), \bar{N}\left(t^{H}\right)\right)\right] \nu_{0}\left(x_{0}\right) d x_{0}=0 .
\end{aligned}
$$

The optimal harvesting time $t^{H}$ can therefore be calculated from the characteristic curves and the total number of individuals, that is, from the solution to system $(\mathrm{h})=(1) \cup(2)$ and the initial distribution of the individuals, $\nu_{0}(x)$. The expression in brackets in equation (9) is similar to that one in equation (5). The existence of local maximum $t^{H}$ of the revenue function $\Pi$ among the solutions of (9) is guaranteed by following the same reasoning given for the size-homogeneous model. Again, this local maximum is global if $\Pi\left(t^{H}\right) \geq \Pi\left(t_{0}\right)$, that is, when it is profitable to culture fish after the growth depensation period.

\section{Empirical application.}

5.1. Shrimp culture in fresh water in Mexico. To obtain an empirical estimation of the above models, information was used from 
two experiments involving different stocking densities of shrimp culture in fresh water. Both experiments were carried out at the Experimental Unit of the University Marista de Mérida, Mexico. In the first one, densities of 90,130 and 180 shrimps $/ \mathrm{m}^{2}$ were stocked, with an average shrimp size of $0.48 \pm 0.03 \mathrm{~g}$. The initial densities for the second experiment were 230, 280, and 330 shrimps $/ \mathrm{m}^{2}$ with an average size of $0.41 \pm 0.04 \mathrm{~g}$. Juvenile shrimps were randomly distributed in nine tanks, with three samples for each treatment. Organisms were fed with balanced feed supplied by Purina (Camaronina, Agribrands, Mexico), with a protein content of $35 \%$. Water temperature and the concentration of dissolved oxygen were measured three times daily, while nitrites, $\mathrm{pH}$ and nonionized ammonia were measured weekly. Weight and mortality were also estimated weekly. More details of the experimental conditions can be found in Araneda et al. [2008] and Araneda [2010].

5.2. Model estimation. The growth function (1) was estimated from the data. Various standard expressions were tested, such as those of von Bertalannfy and by Gompertz, slightly modified to include the density effect. The best statistical results were obtained with the function

$$
g(x, \bar{N})=0.056 e^{-0.030\left(L_{n}(\bar{N})\right)^{2}} x^{0.60}-0.003 x \operatorname{Ln}(x),
$$

where $A$ is the total culture area $\left(A=40,132 \mathrm{~m}^{2}\right)$. The mortality rate was assumed to be exclusively dependent on the total number of individuals. The estimated function is $\mu(\bar{N})=$ $1 / A\left(-099+\operatorname{Ln}(\bar{N} / A)^{-0.008}\right)$. The statistical results showed that all the parameters are significant and with the expected sign, that is, positive with a probability higher than 0.95 . To validate the model, a comparison analysis of the estimated growth and mortality with the empirical data was performed and satisfactory results were obtained (see the Appendix).

To confirm the reliability of system $(\mathrm{H})$, the existence of a growth depensation period for the empirical data was tested. Samples of sizes for the different treatments were stratified into three groups (small, medium, and large) and equation (4) was tested by changing time 
TABLE 1. Estimated growth depensation period $\left(t_{0}\right)$, mean size $\left(\bar{x}_{0}\right)$, regression coefficient $\gamma$ (equation $(11))$, range of sizes at time $t_{0}\left(\left[x_{0}^{0}, x_{0}^{1}\right]\right)$ and size distribution at time $t_{0}$ (equation (12)) for six different initial culture densities.

\begin{tabular}{|c|c|c|c|c|c|c|}
\hline \multirow[b]{2}{*}{$\begin{array}{l}\text { Initial density } \\
\text { (individuals } / \mathrm{m}^{2} \text { ) }\end{array}$} & \multicolumn{3}{|c|}{ Growth depensation } & \multicolumn{3}{|c|}{ Size distribution at time $t_{0}$} \\
\hline & $\begin{array}{l}\bar{x}_{0} \\
(\mathrm{~g})\end{array}$ & $\begin{array}{c}t_{o} \\
(\text { days })\end{array}$ & $\gamma^{\mathrm{a}}$ & $\begin{array}{c}{\left[x_{0}^{0}, x_{0}^{1}\right]} \\
\quad(\mathrm{g})\end{array}$ & $\alpha^{\mathrm{b}}$ & $\beta$ \\
\hline 90 & 2.21 & 35 & 1.071 & {$[1.54,4.02]$} & 1.814 & 1.835 \\
\hline 130 & 2.14 & 42 & 1.111 & {$[1.78,4.07]$} & 2.988 & 3.164 \\
\hline 180 & 2.50 & 70 & 1.162 & {$[1.09,5.31]$} & 4.018 & 2.794 \\
\hline 230 & 2.55 & 77 & 0.946 & {$[2.40,4.95]$} & 2.360 & 2.895 \\
\hline 280 & 2.43 & 84 & 1.079 & {$[1.52,5.46]$} & 2.648 & 3.691 \\
\hline 330 & 2.38 & 84 & 1.054 & {$[1.43,4.61]$} & 2.400 & 2.401 \\
\hline
\end{tabular}

${ }^{a}$ Estimated regression coefficient (equation (11)) for time $t_{0}$ indicated in the previous column. The $p$-values are lower than 0.0001 for the six initial densities analyzed, showing that parameter $\gamma$ is not different to one at a $99.9 \%$ level of significance. The coefficient of determination $R^{2}$ ranges between 0.833 and 0.913 . ${ }^{\mathrm{b}}$ Estimated values for the parameters of the beta function (equation (12)). The Kolmogorov-Smirnov test for goodness of fit was performed, accepting the null hypotheses of agreement of data distribution with the beta distribution function at $0.05 \%$ level of significance.

$t_{0}$ from the stocking time onwards. A simple linear regression model relating both sides of equation (4) was then tested,

$$
\frac{C V(t)}{C V\left(t_{0}\right)}=\gamma\left[\frac{\widehat{g}(\bar{x}) / \bar{x}}{\widehat{g}\left(\bar{x}_{0}\right) / \bar{x}_{0}}\right]+\varepsilon,
$$

where $\gamma$ is the regression coefficient and $\varepsilon$ is the residual. The results for the different treatments are presented in the first four columns of Table 1 , showing the time $t_{0}$ when the estimated regression coefficient was closest to one. As can be observed, this initial time varies with the treatments, but the corresponding initial mean size falls by 2.14 to $2.55 \mathrm{~g}$. The coefficient of determination $R^{2}$ was higher than $80 \%$ and parameter $\gamma$ was not different to one, at a $99.9 \%$ level of significance. 
These results suggest that a cohort growth depensation period is present until the mean size reaches values slightly over $2 \mathrm{~g}$.

To check the fitness of the growth equation (10) to the stratified data, a validation test was carried out. The results show that better validation results are obtained by assuming heterogeneous growth from time $t=t_{0}$ than by assuming homogeneous growth from the beginning of the culture (see the Appendix).

As shown in Table 1 , the estimated time $t_{0}$ is positively dependent on the initial culture density. The higher the initial number of individuals in the cage or pond, the longer the growth depensation period. The size distribution at this time represents the initial distribution $\nu_{0}(x)$ in system $(\mathrm{H})$. A beta function was chosen to describe $\nu_{0}(x)$ for all the treatments, since this function is positive in a bounded interval and can adopt multiple graphical forms. Therefore, the initial distribution follows the expression

$$
\begin{aligned}
& \nu_{0}(x)=\frac{1}{x_{0}^{1}-x_{0}^{0}} \frac{\Gamma(\alpha+\beta)}{\Gamma(\alpha) \Gamma(\beta)}\left(\frac{x-x_{0}^{0}}{x_{0}^{1}-x_{0}^{0}}\right)^{\alpha-1}\left(1-\frac{x-x_{0}^{0}}{x_{0}^{1}-x_{0}^{0}}\right)^{\beta-1} \\
& x_{0}^{0}<x<x_{0}^{1}
\end{aligned}
$$

and is zero in the remaining values of $x . \Gamma(\cdot)$ is the gamma function, $\alpha$ and $\beta$ are the beta function parameters and $x_{0}^{0}$ and $x_{0}^{1}$ are the minimum and maximum sizes at the initial time $t_{0}$. The last three columns of Table 1 show the parameter estimations of the beta distribution for each treatment.

Before analyzing the economic implications of the size heterogeneity, a simulation of systems $(\mathrm{h})$ and $(\mathrm{H})$ is presented. The numerical solution of the nonlinear size-structured model (3) was obtained by implementing the algorithm proposed by Angulo and López-Marcos [2004] in MATLAB. The time and size step were set at 1 day and $0.01 \mathrm{~g}$, respectively. Figure 2 shows the number of individuals after 400 days of culture for three different initial densities. The concave curves represent the size distribution at time $t^{*}=400$ obtained by applying the size-heterogeneous model $(\mathrm{H})$, while the thick vertical lines indicate the average size at the same time obtained with the size homogeneous model (h). Thus, for example, assuming a stocking 


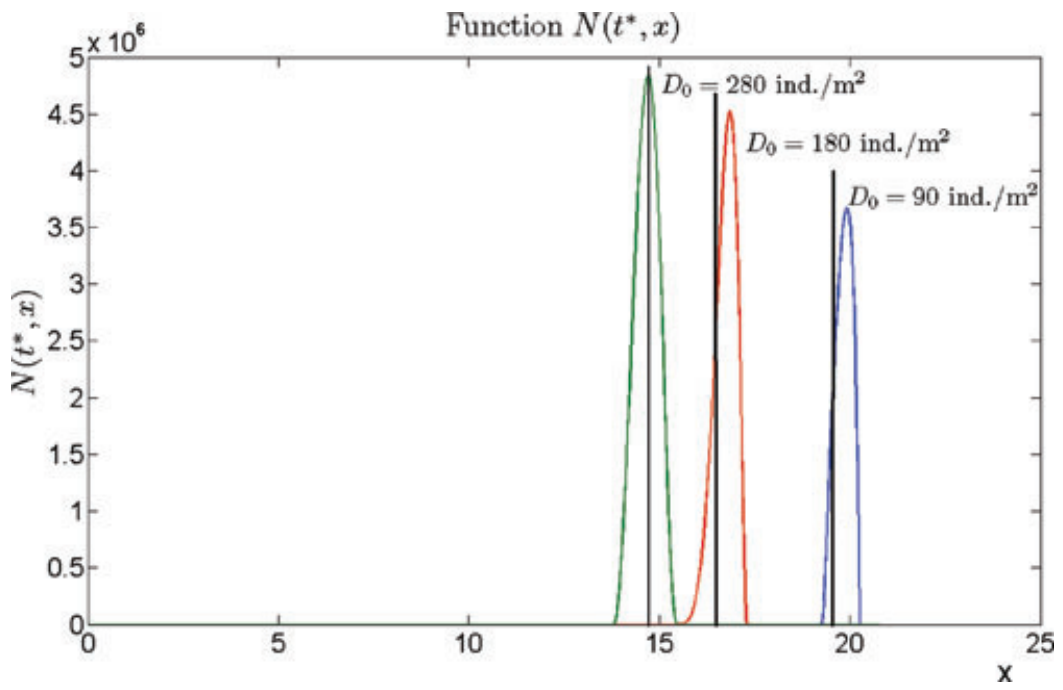

FIGURE 2. The number of individuals $N\left(t^{*}, x\right)$ after $t^{*}=400$ days of culture for three different initial densities $\left(D_{0}\right)$. The concave colored curves represent the size distribution obtained with system $(\mathrm{H})$ and the thick vertical lines indicate the final size obtained with system $(\mathrm{h})$. Notation ind. $/ \mathrm{m}^{2}$ means individuals $/ \mathrm{m}^{2}$.

density of 90 individuals $/ \mathrm{m}^{2}$, the average size reached at time $t^{*}=400$ by using system (h) is $x^{h}=19.58 \mathrm{~g}$, which decreases to $x^{h}=14.74 \mathrm{~g}$ when the stocking density is 280 individuals $/ \mathrm{m}^{2}$. Therefore, higher culture densities give rise to lower sizes for the same culture span. However, size variability obtained with system $(\mathrm{H})$ increases with the stocking density, as indicated by calculating at time $t^{*}=400$ the coefficient of variation, which shows figures of 0.0105 and 0.0202 for the stocking density of 90 and 280 individuals $/ \mathrm{m}^{2}$, respectively.

Figure 3 shows the evolution of the number of individuals during the same culture cycle for the initial density of 180 individuals $/ \mathrm{m}^{2}$, so the growth depensation period is $t_{0}=70$ days (see Table 1 ). The particular S-shaped growth function with respect to size is the origin of the two clearly apparent stages in the distribution of sizes within the culture span. As shown in the three dimensional surface, the initial distribution of sizes flattens in the middle of the culture cycle (at around 150-200 


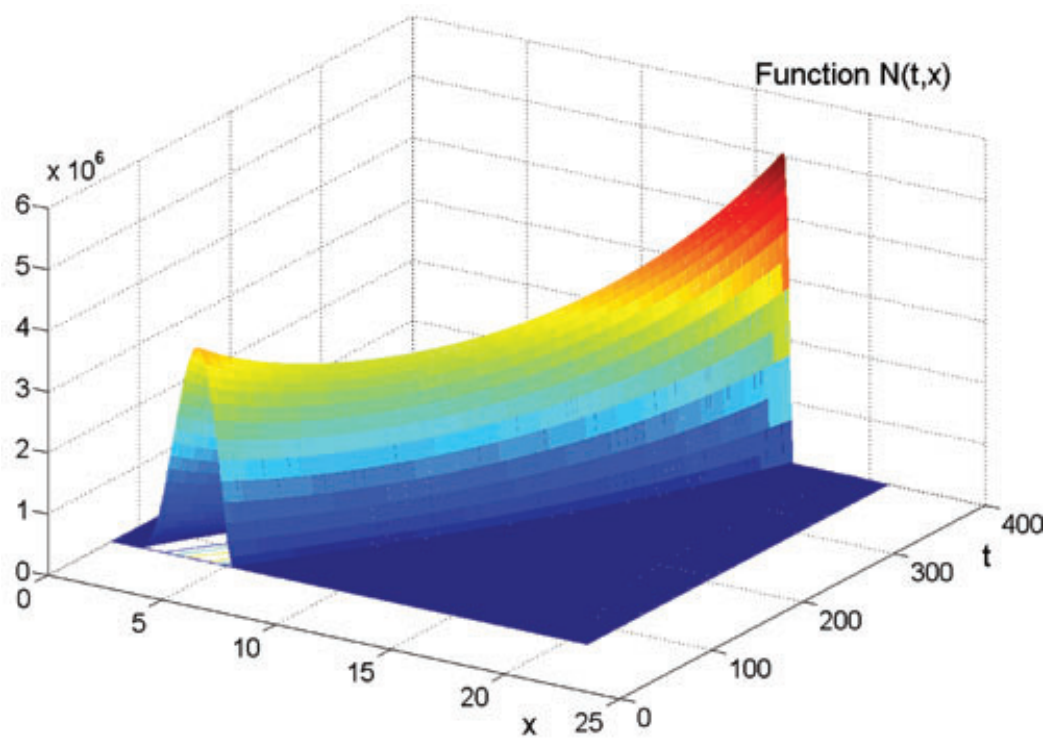

FIGURE 3. The number of individuals for the stocking density of 180 individuals $/ \mathrm{m}^{2}$, starting from $t_{0}=70$ until $t^{*}=400$ days.

days) and is increasingly pointed at the end of the period. As shown in Figure 2, the shape of the density distribution influences on the size variability of the culture. This phenomenon is not captured by homogeneous-growth models such as system (h) and can influence the optimal time to harvest all the individuals.

5.3. Determining the economic parameters. In this study, a recirculation system for the intensive culture of shrimp in fresh water is assumed. Two main sources of costs are considered: (a) Global harvesting cost, $c_{G}$, which is the sum of the harvesting cost $\left(c_{h}\right)$, commercialization $\left(c_{c}\right)$, and miscellanea $\left(c_{m i}\right)$ per individual; (b) Operational costs $C(x, \bar{N})$, which are divided into fixed, maintenance, feeding, and energy cost per individual. The global harvesting cost is constant and subtracted from the price, while the operational cost follows the 
expression,

$$
C(x, \bar{N})=c_{F} \bar{N}+c_{m} x+c_{f} f(x, \bar{N})+c_{e}\left(E_{p}(x, \bar{N})+E_{a}(x, \bar{N})\right),
$$

where $c_{F}$ represents the individual's fixed cost, $c_{m}$ is the cost per gram of maintaining a $x$-size organism in the closed system of production (cost related to feeding management, replacements and registers of water quality, biometrics and equipment control), $c_{f}$ is the feeding cost per gram and $c_{e}$ is the unit cost of energy. Function $f(x, \bar{N})$ represents the amount of food supplied to an organism of size $x$, which also depends on culture density. Functions $E_{p}(x, \bar{N})$ and $E_{a}(x, \bar{N})$ are the necessary pumping and aeration energy per individual of size $x$, respectively. The cost parameter estimations are shown in Table 2, together with the other economic parameters.

The quantity of food supplied to each organism depends on the conversion rate, that is, the amount of food necessary to achieve a 1 gram size increase, which is represented by $\xi(x, \bar{N})$. This parameter depends on size and density. The function for the conversion rate, which was estimated from the experimental information, is

$$
\xi(x, \bar{N})=0.221 \operatorname{Ln}(\bar{N} / A) x^{0.288}
$$

Hence, the total amount of food per individual is described by

$$
f(x, \bar{N})=\xi(x, \bar{N}) g(x, \bar{N}) .
$$

The water pumping rate was estimated using the recycling principle proposed by Huguenin and Colt [2002]. The daily ammonia production $\left(P_{T A N}\right)$ corresponds to the total amount of food supplied, $P_{T A N}=$ $\delta \cdot f(x, \bar{N})$, where $\delta=0.03$ is the ammonia production rate (van Wyk et al. [1999]). Making use of the percentage of recirculated water $(\chi)$ and the degree of biofilter efficiency $\left(E_{f B}\right)$, an estimation of ammonia transport $\left(M_{b}\right)$ is obtained, which follows the expression

$$
M_{b}(x, \bar{N})=\frac{\delta f(x, \bar{N})}{1-\chi\left(1-E_{f_{B}}\right)} .
$$


TABLE 2. Economic parameter assumptions for the shrimp market in Yucatan, Mexico.

\begin{tabular}{|c|c|c|c|c|}
\hline Parameter & Description & Magnitude & Value & Source \\
\hline$c_{f}$ & Feeding cost & $\mathrm{US} \$ / \mathrm{g}$ & 0.00073 & Local Market $^{\mathrm{a}}$ \\
\hline$c_{e}$ & Energy cost & $\mathrm{US} \$ / \mathrm{kw}-\mathrm{hr}$ & 0.05 & Local Market \\
\hline$c_{m}$ & Maintenance cost & $\mathrm{US} \$ / \mathrm{g}$ & 0.0000010 & Calibration $^{\mathrm{b}}$ \\
\hline$c_{F}$ & Fixed cost & US\$/individual & 0.0000565 & Calibration \\
\hline$c_{h}$ & Harvesting cost & $\mathrm{US} \$ / \mathrm{g}$ & 0.0002 & Local Market \\
\hline$c_{c}$ & $\begin{array}{l}\text { Commercialization } \\
\text { cost }\end{array}$ & $\mathrm{US} \$ / \mathrm{g}$ & 0.00015 & Local Market \\
\hline$c_{m i}$ & Miscellanea cost & $\mathrm{US} \$ / \mathrm{g}$ & 0.00010 & Local Market \\
\hline$r$ & $\begin{array}{l}\text { Annual discount } \\
\text { rate }\end{array}$ & & 0.08 & Assumption \\
\hline$d_{1}$ & Maximum price & $\mathrm{US} \$ / \mathrm{g}$ & 0.00897 & Estimation $^{\mathrm{c}}$ \\
\hline$d_{2}$ & Price parameter & & 0.27338 & Estimation \\
\hline$d_{3}$ & Price parameter & & 3.02968 & Estimation \\
\hline
\end{tabular}

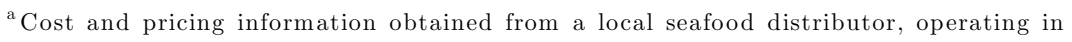
the Yucatan Peninsula.

${ }^{\mathrm{b}}$ Fixed and maintenance costs are calculated according to their percentage in the total cost for a typical farm of $40,132 \mathrm{~m}^{2}$ and culture density of $90 \mathrm{shrimp} \cdot \mathrm{m}^{-2}$ in Yucatan State. In these farms, fixed costs represent $32.05 \%$ of the total, while maintenance costs account for $12.32 \%$.

${ }^{c}$ The price function parameters (equation (13)) were estimated by fitting the logistic function to market data using the Levenberg-Marquardt iterative method to solve the nonlinear least squares problem.

The denominator of this expression is positive in conditions of recirculation and non-null efficiency of the water biofiltration processes $(\chi>$ $\left.0 \%, E_{f B}>0 \%\right)$. The maximum amount of ammonia tolerated $\left(C_{\max }\right)$, which is dependent on the specific species, was used to calculate the necessary water circulation in the system, $Q_{\text {total }}=M_{b}(x, \bar{N}) / C_{\max }$. The daily energy requirement was derived from this variable, the manometer height of the system $\left(H_{m}\right)$, the constant power unit $(\kappa)$ and the pumping efficiency $(\eta)$. Thus,

$$
E_{p}(x, \bar{N})=\frac{a_{g} \cdot H_{m} \cdot Q_{t o t a l}(x, \bar{N})}{\kappa \cdot \eta},
$$


where $a_{g}=9.81$ is the acceleration of gravity. The aeration energy requirement was calculated from the estimated oxygen demand $\left(M_{o}\right)$ and the efficiency of oxygen transfer $(E)$. The following equation was used for the oxygen demand,

$$
M_{o}(x, \bar{N})=\alpha \cdot O_{F R} \cdot \mathrm{f}(x, \bar{N}),
$$

where $\alpha$ is the oxygen demand factor (Huguenin and Colt [2002]), which is multiplied by the oxygen requirement $\left(O_{F R}\right)$ for each gram of food supplied. The efficiency of oxygen transfer was estimated by assuming submerged aerators (Colt and Tchobanoglous [1981]) and is independent of size and density. Hence, the aeration energy is

$$
E_{a}(x, \bar{N})=\frac{M_{o}(x, \bar{N})}{E} .
$$

The value, description and source of the technical parameters are presented in Table 3.

To find the optimal harvesting time of a single culture, the price structure must also be known. Price information for different sizes of fresh whole shrimp in August to September 2008 was obtained from a Yucatan seafood distributor, revealing that shrimp price depends on the size of the individual. From the real data, a direct relationship between price per gram and size was estimated by means of a logistic function. Thus,

$$
p(x)=\frac{d_{1}}{1+d_{2} e^{-d_{3} x}},
$$

where $d_{1}$ represents the maximum price, and $d_{2}$ and $d_{3}$ are function parameters. The values for the price parameters are shown in Table 2. The Appendix includes the details of the price data and estimation procedure.

5.4. Calculation of optimal harvesting times. The optimal harvesting time for a single shrimp culture cycle in intensive recirculation systems with fresh water was calculated. The two models described above (size-homogeneous and size-heterogeneous) were used 


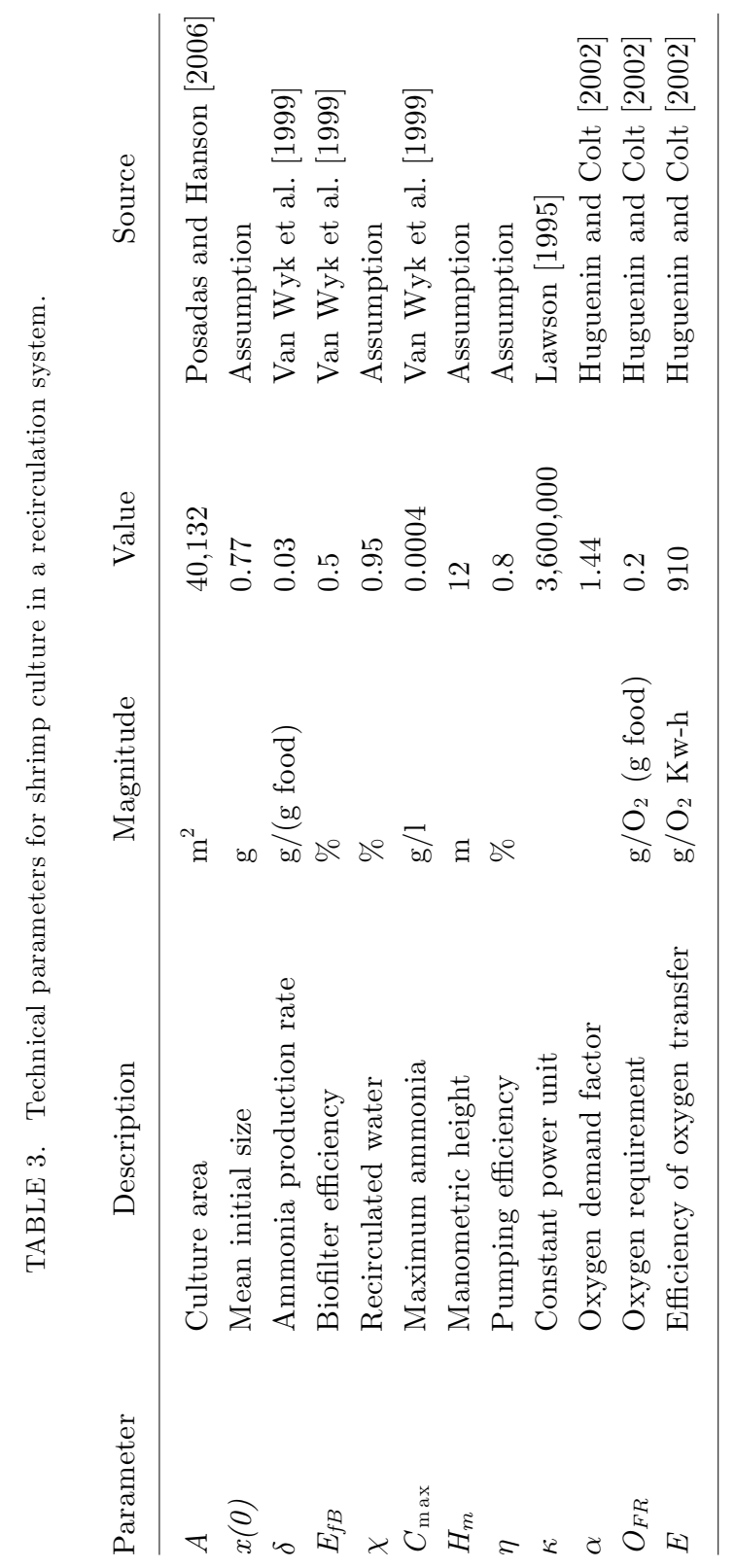


TABLE 4. Optimal harvesting time $\left(t^{h}\right.$ and $\left.t^{H}\right)$ and size (mean $x^{h}$ and interval $\left.\left[x_{\mathrm{min}}^{H}, x_{\mathrm{max}}^{H}\right]\right)$ for six different initial densities of shrimp culture in Mexico using the size-homogeneous model $(\mathrm{h})$ and size-heterogeneous model $(\mathrm{H})$, respectively.

Size-dependent price $p(x)=0.00897 /\left(1+3.02968 e^{-0.27338 x}\right)$.

\begin{tabular}{|c|c|c|c|c|c|}
\hline \multirow[b]{2}{*}{$\begin{array}{l}\text { Initial density } \\
\text { (individuals } / \mathrm{m}^{2} \text { ) }\end{array}$} & \multicolumn{2}{|c|}{$\begin{array}{c}\text { Size-homogeneous } \\
\text { model }(h)\end{array}$} & \multicolumn{2}{|c|}{$\begin{array}{c}\text { Size-heterogeneous } \\
\text { model }(H)\end{array}$} & \multirow[b]{2}{*}{$\%$ Utility } \\
\hline & $\begin{array}{c}t^{h} \\
\text { (days) }\end{array}$ & $\begin{array}{l}x^{h} \\
(g)\end{array}$ & $\begin{array}{c}t^{H} \\
(\text { days })\end{array}$ & $\begin{array}{c}{\left[x_{\min }^{H}, x_{\max }^{H}\right]} \\
(\mathrm{g})\end{array}$ & \\
\hline 90 & 348 & 18.05 & 331 & {$[17.13,18.50]$} & 3.68 \\
\hline 130 & 328 & 15.75 & 308 & {$[14.75,16.13]$} & 5.49 \\
\hline 180 & 316 & 13.95 & 304 & {$[11.80,14.73]$} & 5.05 \\
\hline 230 & 309 & 12.72 & 298 & {$[11.80,13.38]$} & 5.79 \\
\hline 280 & 305 & 11.82 & 308 & {$[10.60,13.13]$} & -1.56 \\
\hline 330 & 301 & 11.07 & 303 & {$[9.81,12.05]$} & -1.61 \\
\hline
\end{tabular}

${ }^{a}$ This column represents the difference in percentage terms between the maximum profit obtained with the size-heterogeneous model and the maximum profit obtained with the size-homogeneous model.

independently, but assuming identical technical and economic conditions. The algorithms to solve equations (5) and (9) were implemented in MATLAB and the time and size step were set to be 1 day and 0.01 $\mathrm{g}$, respectively.

The results for the six densities tested in the experiment are presented in Table 4. As can be seen, the optimal harvesting time decreases for higher densities when identical growth among individuals is assumed. The reduced rates of growth with higher densities make it more profitable to harvest the culture earlier. However, this rule varies in the case of the size-heterogeneous model. In this case, the harvesting time is density-decreasing for the lowest culture densities analyzed (90-230 individuals $/ \mathrm{m}^{2}$ at the beginning of the culture), but this behavior changes abruptly for higher densities (280-330 individuals $\left./ \mathrm{m}^{2}\right)$. The high variability of the initial distribution of sizes for these stocking strategies (see Table 1) and the nonlinear size-dependent price influence this numerical outcome. In the specific price function used in 
the estimations of Table 4, the price per gram increases steeply, to stabilize at sizes above $12 \mathrm{~g}$. Since greater culture density is associated with reduced growth rates, it may be more profitable to allow the individuals a few more days to grow in order to take advantage of the higher prices obtained with larger sizes. Such is the case with the highest initial culture densities considered in Table 4 (280 and 330 individuals $/ \mathrm{m}^{2}$ ), which reach optimal sizes between 9.81 and $13.13 \mathrm{~g}$. On the contrary, the optimal harvesting sizes for the other culture densities are all above $11.80 \mathrm{~g}$. This phenomenon is not reflected by system (h), since marginal revenues obtained with different sizes at the same time are not taken into account with the size-homogeneous hypothesis.

The relationship between the optimal harvesting times obtained by each model is also ambiguous. For the lowest densities considered in the numerical analysis, the optimal harvesting times under the hypothesis of size-homogeneity are larger than those given by the sizeheterogeneity model $\left(t^{H}<t^{h}\right)$. The largest difference between these estimations is found for an initial culture density of 130 individuals $/ \mathrm{m}^{2}$, amounting to 20 days, which corresponds to an error of $6.49 \%$ in the harvesting time recommendations if the size-heterogeneity phenomenon is not taken into account. This error is reduced for higher densities and the relation $t^{H}<t^{h}$ is reversed for the largest stocking densities (280 and 330 individuals $/ \mathrm{m}^{2}$ ).

The size-dependent price assumed in the baseline case may also influence the difference and the ordinal relation between the optimal harvesting times derived from the two models. To show this, Table 5 presents the estimations obtained when constant or size-independent prices are assumed. Two scenarios of low and high constant prices were considered, corresponding to two prices for the continuous function $p(x)$ in Table 4, one in the increasing phase and the other slightly over the asymptotic value of $p(x)$, respectively. As can be observed in Table 5 panel a and $\mathrm{b}$, the optimal harvesting times are nonincreasing with respect to density in both models and present a wider range of values than those obtained with the size-dependent price. For example, the optimal harvesting times range from 165 to 289 days with the sizehomogeneous model and from 166 to 270 with the size-heterogeneous model, assuming $p=U S \$ 0.007$. These figures increase if a price of $p=U S \$ 0.009$ is assumed, and then range from 206 to 324 and 
TABLE 5. Optimal harvesting time $\left(t^{h}\right.$ and $\left.t^{H}\right)$ and size (mean $x^{h}$ and interval $\left.\left[x_{\mathrm{min}}^{H}, x_{\mathrm{max}}^{H}\right]\right)$ for six different initial densities of shrimp culture in Mexico using the size-homogeneous model (h) and size-heterogeneous model $(\mathrm{H})$, respectively: (a)

Constant price $p=$ US $\$ 0.007$ per g; (b) Constant price $p=$ US $\$ 0.009$ per g.

\begin{tabular}{|c|c|c|c|c|c|}
\hline \multirow[b]{2}{*}{$\begin{array}{l}\text { Initial density } \\
\text { (individuals } / \mathrm{m}^{2} \text { ) }\end{array}$} & \multicolumn{2}{|c|}{$\begin{array}{l}\text { Size-homogeneous } \\
\text { model }(h)\end{array}$} & \multicolumn{2}{|c|}{$\begin{array}{c}\text { Size-heterogeneous } \\
\text { model }(H)\end{array}$} & \multirow[b]{2}{*}{$\%$ Utility $^{a}$} \\
\hline & $\begin{array}{c}t^{h} \\
\text { (days) }\end{array}$ & $\begin{array}{l}x^{h} \\
(\mathrm{~g})\end{array}$ & $\begin{array}{c}t^{H} \\
(\text { days })\end{array}$ & $\begin{array}{c}{\left[x_{\min }^{H}, x_{\max }^{H}\right]} \\
(\mathrm{g})\end{array}$ & \\
\hline \multicolumn{6}{|l|}{ (a) } \\
\hline 90 & 289 & 15.83 & 270 & {$[14.56,16.43]$} & 5.47 \\
\hline 130 & 252 & 12.70 & 230 & {$[11.31,13.27]$} & 8.63 \\
\hline 180 & 221 & 10.11 & 206 & {$[7.06,11.27]$} & 8.33 \\
\hline 230 & 199 & 8.37 & 184 & {$[6.96,9.34]$} & 9.59 \\
\hline 280 & 181 & 7.07 & 183 & {$[5.27,9.12]$} & -1.73 \\
\hline 330 & 165 & 6.04 & 166 & {$[4.23,7.5]$} & -1.43 \\
\hline \multicolumn{6}{|l|}{ (b) } \\
\hline 90 & 324 & 17.21 & 306 & {$[16.51,17.71]$} & 3.80 \\
\hline 130 & 287 & 14.20 & 266 & {$[12.99,14.68]$} & 5.82 \\
\hline 180 & 258 & 11.72 & 243 & {$[8.93,12.68]$} & 5.40 \\
\hline 230 & 237 & 9.97 & 222 & {$[8.65,10.79]$} & 6.07 \\
\hline 280 & 220 & 8.65 & 222 & {$[6.98,10.46]$} & -1.12 \\
\hline 330 & 206 & 7.62 & 207 & {$[5.90,8.98]$} & -0.95 \\
\hline
\end{tabular}

${ }^{a}$ This column represents the difference in percentage terms between the maximum profit obtained with the size-heterogeneous model and the maximum profit obtained with the size-homogeneous model.

from 207 and 306, respectively. However, the optimal harvesting times are later, between 301 and 348 days, when a size-dependent price is assumed. This observation illustrates the influence of the sizedependent price structure on the recommended harvesting time for farmers.

As expected, harvesting time and size are positively influenced by price (Table 5 panel a and b). The results in this respect show a 
similar pattern to the case of size-dependent price in terms of the comparison between the estimated optimal harvesting times when sizehomogeneity and heterogeneity, respectively, are assumed. The maximum difference between the harvesting times calculated from both models again corresponds to an initial culture density of 130 individuals $/ \mathrm{m}^{2}(p=U S \$ 0.007)$ with 22 days, which represents a percentage error of $8.73 \%$. Similarly, the ordinal relation between the calculated optimal harvesting times for the two models reveals that $t^{H}<t^{h}$ for the low initial densities considered, and is reversed for the highest densities. These results indicate that assuming constant or size-dependent prices in the study case does not greatly influence the relationship of the optimal harvesting time under the size-homogeneous or heterogeneous hypotheses. Other numerical simulations indicate that the change in the ordinal relation between $t^{h}$ and $t^{H}$ is associated with low growth rates for large culture densities.

The last column in Tables 4 and 5 shows the percentage difference between the discounted utility estimated by assuming size-homogeneity or heterogeneity, respectively, in the culture. To calculate the net revenue for the size-heterogeneous case, system (h) was considered during the growth depensation period, that is, from $t=0$ to $t=t_{0}$, where $t_{0}$ is the initial time indicated in Table 1 ; after that time, system $(\mathrm{H})$ was used. The values shown in Table 4 and 5 indicate that, for initial culture densities of 90-230 individuals $/ \mathrm{m}^{2}$, the net revenue is underestimated if the homogeneous growth hypothesis is adopted. This error increases for low values of the price and high culture densities in this range. Again, the results are reversed for the largest densities analyzed (280 and 330 individuals $/ \mathrm{m}^{2}$ ). In these cases, the optimal harvesting times are slightly overestimated when the size-homogeneous model is used. Numerical simulations show that the high dispersion of the initial distribution of sizes and the low growth rates associated with large culture densities can explain this outcome. Due to these factors, the percentage variability of sizes at the harvesting time is high and consequently the estimated revenues are lower than those derived under the size-homogeneous hypothesis.

6. Discussion and conclusions. This paper presents an estimation of the optimal harvesting time in aquaculture management, when the size-heterogeneity phenomenon is included in the calculations. A 
nonlinear size-structured model was assumed to represent the population dynamics, in which both the growth and the mortality rate depend on the size and the total number of individuals. A necessary condition for the optimal harvesting time was analytically obtained; this is an extension of previous results, based on more simplistic size-homogeneity assumptions or on linear size-structured models.

A traditional (assuming size-homogeneity) and a size-structured model were adjusted to experimental data for shrimp culture in recirculation systems in Mexico, for six levels of culture density. The estimations show that the size-structured model fits the data from a certain time after the beginning of the culture, approximately when the mean size of the culture surpasses a given threshold. Above this mean size, the nonlinear size-structured model is a good approximation of the data.

The calculated optimal harvesting times in the case study, for the size-homogeneous model, show decreasing values with respect to density. Although the theoretical effect of the culture density on the optimal harvesting time is ambiguous, as revealed in equation (5), the results from the case study suggest the shrimp should be harvested earlier if the culture density is increased. However, this rule does not hold if size-heterogeneity is assumed in the model formulation. In this case, the optimal harvesting time increases slightly for very large culture densities, when a size-dependent price is assumed. Numerical simulations indicate that the slow growth rates derived from large densities, combined with the high variability of initial sizes after the growth depensation period observed in these stocking strategies, are the major factors delaying the optimal harvesting time.

In general, the discounted net revenue is underestimated if sizehomogeneity in the culture is assumed. Moreover, the calculated harvesting time shortens the predictions based on the homogeneous growth hypothesis. The latter observation does not match the findings obtained by Gasca-Leyva et al. [2008], who analytically proved, under certain price and cost conditions, that the optimal harvesting time when homogenous population growth is assumed must be lower than that derived from a linear size-structured population. The density-dependence growth included in this paper produces a reversal of the relationship between the calculated optimal harvesting times in the case study. 
Although the relationships between the most profitable harvesting times obtained with the two approaches would not necessary hold for other species, cultures or financial conditions, the empirical example presented in this paper illustrates that management decisions in intensive aquaculture farms could be significantly mistaken if a nonrealistic size-homogeneous growth hypothesis is assumed.

The model formulation and the conclusions reached can be applied to other husbanded biological populations, such as forestry or other cultured animals. Moreover, the research can be extended to areas such as the rotation problem (the consideration of subsequent culture cycles for a predetermined time horizon), which has yet to be studied in the context of continuous size-structured populations. In addition, the question of selective harvesting (e.g., larger sizes of a same cohort) during a single culture span has not been subjected to any in-depth analysis with these models. Recent results for the theory of optimal control with continuous size-structured models could be used to solve the problem in the same framework as that presented in this paper.

\section{ENDNOTES}

1. Most studies on optimal harvesting time in aquaculture production refer to fish culture. However, the results presented in this paper can be directly extended to the context of other cultured species, such as crustaceans.

2. In the context of the optimal management of renewable resources, this kind of model is called a lumped-parameter or biomass model (Clark [1990], Tahvonen [2009]).

3. Strictly speaking, the characteristic curve also depends on $\bar{N}_{0}$. For simplicity, this argument is omitted.

4. For simplicity, $\bar{N}^{\prime}$ in the argument of the solution is omitted.

Acknowledgments. The authors thank the editor and three anonymous reviewers for their valuable suggestions on an earlier version of the paper. This research was financed by the Government of Spain, Grant PCI A/8022/07 and SEJ2006-15408/ECON. Preliminary versions were presented at the Workshop "Age-structured models in fishery economics and bioeconomic modeling," University of Trondheim, Norway, August 2009, and at the International Institute of Fisheries 
Economics and Trade Conference, Montpellier, July 2010. The authors thank the participants at both meetings for their comments and suggestions.

\section{APPENDIX}

General solution for the nonlinear size-structured model. Without loss of generality, $t_{0}=0$ and $x_{0}=0$ in equations (1) and (3) are assumed. Thus, the number of individuals of size $x$ at time $t, N(t, x)$, follows

$$
\begin{aligned}
N_{t}(t, x) & +(g(x, \bar{N}) N(t, x))_{x}=-\mu(\bar{N}) N(t, x), 0<x<\omega, t>0, \\
(\mathrm{~A} 1) \quad & N(0, x)=\bar{N}_{0} \nu_{0}(x), \\
N(t, 0) & =0 .
\end{aligned}
$$

where $g:[0, \omega] \times[0,+\infty) \rightarrow \Re^{+}$is a bounded and continuously differentiable function on $[0, \omega] \times[0,+\infty)$ and strictly positive on $[0, \omega] \times$ $[0,+\infty), \mu:[0,+\infty) \rightarrow \Re^{+}$is a bounded non-negative continuously differentiable function and $\nu_{0}:[0,+\infty) \rightarrow \Re^{+}$is non-negative and integrable.

Model (A1) is an extension of model (2). By integrating the left-hand side of equation (A1) with respect to size, it follows that

$$
\begin{aligned}
& \int_{0}^{\omega}\left(N_{t}(t, x)+(g(x, \bar{N}) N(t, x))_{x}\right) d x \\
& \left.\quad=\int_{0}^{\omega} \frac{d N}{d t}(t, x) d x+g(x, \bar{N}) N(t, x)\right]_{0}^{\omega} \\
& \quad=\frac{d}{d t} \int_{0}^{\omega} N(t, x) d x=\frac{d \bar{N}(t)}{d t},
\end{aligned}
$$

since $g(w, \bar{N})=0$ and $N(t, 0)=0$. Equation (2) follows directly by integrating the right-hand side of equation (A1) with respect to size $x$. 
The solution to equation $(1) \cup(3)$ follows, by definition (see Calsina and Saldaña [1995]), the characteristic equation

$$
\left\{\begin{array}{l}
\dot{x}=g(x, \bar{N}), \\
\dot{\bar{N}}=-\mu(\bar{N}) \bar{N} \\
x\left(t^{\prime}\right)=x^{\prime} ; \bar{N}\left(t^{\prime}\right)=\bar{N}^{\prime}
\end{array}\right.
$$

Let us name $x\left(t ; t^{\prime}, x^{\prime}\right)$, with $t \in[0,+\infty), t^{\prime}, x^{\prime} \in \Re_{0}^{+}$, the solution of $(\mathrm{A} 2)^{4}$ and $\tilde{N}\left(t ; t^{\prime}, x^{\prime}\right) \equiv N\left(t, x\left(t ; t^{\prime}, x^{\prime}\right)\right)$. Differentiating with respect to $t$, gives

$$
\frac{d \tilde{N}}{d t}=\tilde{N}_{t}+\tilde{N}_{x} \dot{x}=\tilde{N}_{t}+\tilde{N}_{x} g=-g_{x} \tilde{N}-\mu \tilde{N}
$$

and integrating this equation from $t=\hat{t}$, the following equation is obtained:

$$
\tilde{N}(t ; t, x)=\tilde{N}(\hat{t} ; t, x) \exp \left\{-\int_{\hat{t}}^{t}\left(g_{x}(x(s ; t, x), \bar{N}(s))+\mu(\bar{N}(s))\right) d s\right\} .
$$

Since $\hat{t}$ should be non-negative, its value depends on the relative position of variables $t$ and $x$ in the above equation. We define $z(t)=$ $x(t ; 0,0)$ as the solution to the characteristic equation crossing the origin (Figure A1). Thus, if $x \geq z(t) \Rightarrow x(0 ; t, x) \geq 0, \hat{t}=0$ is taken. Alternatively, if $x<z(t) \Rightarrow x(0 ; t, x)<0, \hat{t}$ is now the time needed to reach size $x=0$, and this is denoted as $\hat{t}=\tau(0 ; t, x)>0$.

Hence, the solution of (A1) through the characteristic equation is

$$
\begin{aligned}
& N(t, x)= \\
& \left\{\begin{array}{l}
N(\tau(0 ; t, x), 0) \exp \left\{-\int_{\tau(0 ; t, x)}^{t}\left(g_{x}(x(s ; t, x), \bar{N}(s))+\mu(\bar{N}(s))\right) d s\right\} \text { if } x<z(t), \\
N(0, x(0 ; t, x)) \exp \left\{-\int_{0}^{t}\left(g_{x}(x(s ; t, x), \bar{N}(s))+\mu(\bar{N}(s))\right) d s\right\} \text { if } x \geq z(t) .
\end{array}\right.
\end{aligned}
$$




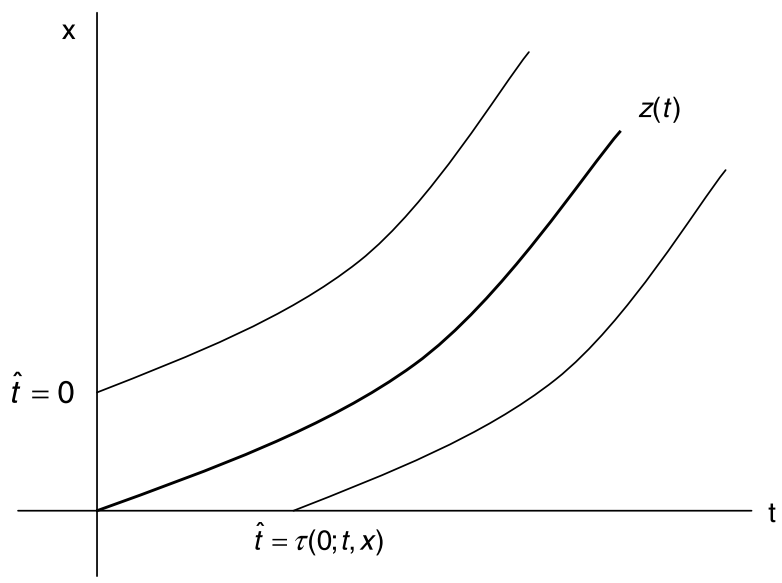

FIGURE A1. Representation of characteristic curves.

In general, species do not reproduce in aquaculture farms during a culture cycle. Therefore, there is no replacement (size $x=0$ ) for $t>0$ and so $N(\tau(0 ; t, x), 0) \equiv 0$, and the above equation simplifies to

$$
\begin{aligned}
N(t, x)= & N(0, x(0 ; t, x)) \\
& \times \exp \left\{-\int_{0}^{t}\left(g_{x}(x(s ; t, x), \bar{N}(s))+\mu(\bar{N}(s))\right) d s\right\}
\end{aligned}
$$

if $x \geq z(t)$, and to zero in the remaining values.

Given the general regularity conditions of the above functions, the existence and uniqueness of solution (A3) is assured (Calsina and Saldaña [1995]).

Lemma 1. Let $t_{0}, t_{1} \in \Re_{0}^{+} \cup\{+\infty\}, t, x \in \Re^{+}, x\left(\cdot ; t^{\prime}, x^{\prime}\right):\left(t_{0}, t_{1}\right) \rightarrow$ $\Re^{+}$be the solution to equation (A2). Then, $\forall t \in\left(t_{0}, t_{1}\right)$,

$$
\frac{\partial x\left(t ; t^{\prime}, x^{\prime}\right)}{\partial x^{\prime}}=\exp \left\{\int_{t^{\prime}}^{t} g_{x}\left(x\left(s ; t^{\prime}, x^{\prime}\right), \bar{N}(s)\right) d s\right\} .
$$


Proof: Differentiating the left-hand side of the equation and applying the Schwarz Theorem,

$$
\begin{aligned}
\frac{d}{d t}\left[\frac{\partial x\left(t ; t^{\prime}, x^{\prime}\right)}{\partial x^{\prime}}\right] & =\frac{\partial}{\partial x^{\prime}}\left[\frac{d}{d t} x\left(t ; t^{\prime}, x^{\prime}\right)\right]=\frac{\partial}{\partial x^{\prime}} g\left(x\left(t ; t^{\prime}, x^{\prime}\right), \bar{N}(t)\right) \\
& =g_{x}\left(x\left(t ; t^{\prime}, x^{\prime}\right), \bar{N}(t)\right) \frac{\partial x\left(t ; t^{\prime}, x^{\prime}\right)}{\partial x^{\prime}}
\end{aligned}
$$

This is a simple linear differential equation $\dot{y}=g_{x}\left(x\left(t ; t^{\prime}, x^{\prime}\right), \bar{N}(t)\right)$. $y$, with $y \equiv \frac{\partial x\left(t ; t^{\prime}, x^{\prime}\right)}{\partial x^{\prime}}$. Integrating with respect to time in $\left[t^{\prime}, t\right]$, it follows that

$$
\begin{aligned}
\frac{\partial x\left(t ; t^{\prime}, x^{\prime}\right)}{\partial x^{\prime}} & =\exp \left\{\int_{t^{\prime}}^{t} g_{x}\left(x\left(s ; t^{\prime}, x^{\prime}\right), \bar{N}(s)\right) d s\right\} \frac{\partial x\left(t^{\prime} ; t^{\prime}, x^{\prime}\right)}{\partial x^{\prime}} \\
& =\exp \left\{\int_{t^{\prime}}^{t} g_{x}\left(x\left(s ; t^{\prime}, x^{\prime}\right), \bar{N}(s)\right) d s\right\} .
\end{aligned}
$$

Validation of the models. For system (h), the initial condition of model (1) was equal to the mean initial size in each tank. The weight trajectories for both the real data and equation (10) were compared, using recommended indicators such as the Coefficient of Determination $R^{2}$, the Root Mean Square Error (RMSE), the Percentage Root Mean Square Error (PRMSE), Theil's inequality coefficient (U), and the decomposition of the Mean Square Error (MSE) in the bias $\left(\mathrm{U}^{\mathrm{M}}\right)$, variance $\left(\mathrm{U}^{\mathrm{S}}\right)$ and covariance components $\left(\mathrm{U}^{\mathrm{C}}\right)$ (Pindyck and Rubinfeld [1981]). The mean values of these statistics for the six initial stocking densities analyzed are presented in the first column of Table A1. As can be observed, the PRMSE is lower than $13 \%$, while Theil's inequality coefficient also presents good results (values close to zero mean a good fit between the simulated and real data). From these results, equation (10) can be considered a representative model of the empirical data.

Table A1 also presents the validation results for equation (10) with the stratified data (small, medium and large) and the initial time at $t=t_{0}$ (Table 1 ). The PRMSE is lower than $9 \%$, while Theil's inequality coefficient remains below 0.04 . The validation indicators reveal that the 
TABLE A1. Validation results for the growth model (10) estimated for the size-homogeneous model $(\mathrm{h})$ and size-heterogeneous model $(\mathrm{H})$, respectively, and mortality function: RMSE = Root Mean Square Error; PRMSE = Percentage

Root Mean Square Error; $\mathrm{U}=$ Theil's inequality coefficient; $\mathrm{U}^{\mathrm{M}}=$ bias proportion; $\mathrm{U}^{\mathrm{S}}=$ variance proportion; $\mathrm{U}^{\mathrm{C}}=$ covariance proportion.

\begin{tabular}{|c|c|c|c|c|c|}
\hline \multirow[b]{2}{*}{ Statistic $^{\mathrm{a}}$} & \multirow{2}{*}{$\begin{array}{c}\text { Growth model, } \\
\text { system }(h)\end{array}$} & \multicolumn{3}{|c|}{ Growth model, system $(H)^{b}$} & \multirow{2}{*}{$\begin{array}{l}\text { Mortality } \\
\text { function }\end{array}$} \\
\hline & & $\mathrm{S}$ & M & $\mathrm{L}$ & \\
\hline RMSE & 0.4330 & 0.4327 & 0.3700 & 0.477 & 34.27 \\
\hline PRMSE & $12.34 \%$ & $8.45 \%$ & $6.66 \%$ & $6.27 \%$ & $12.35 \%$ \\
\hline $\mathrm{R}^{2}$ & 0.9887 & 0.9263 & 0.9536 & 0.9374 & 0.883 \\
\hline Theil (U) & 0.0402 & 0.0391 & 0.0294 & 0.0338 & 0.048 \\
\hline $\mathrm{U}^{\mathrm{M}}$ & 0.3634 & 0.3294 & 0.3268 & 0.3287 & 0.3604 \\
\hline $\mathrm{U}^{\mathrm{S}}$ & 0.1612 & 0.2110 & 0.1414 & 0.3167 & 0.3009 \\
\hline $\mathrm{U}^{\mathrm{C}}$ & 0.5139 & 0.4930 & 0.5651 & 0.3879 & 0.3455 \\
\hline
\end{tabular}

\footnotetext{
${ }^{a}$ Mean values of the statistics calculated for the six stocking densities considered in the empirical application.

${ }^{\mathrm{b}}$ Estimations from the growth depensation period $t=t_{0}$ and stratified data: $\mathrm{S}=$ small; $\mathrm{M}=$ medium; $\mathrm{L}=$ large.
}

estimated size-structured model better fits the empirical data than does the size-homogeneous model. The last column in Table A1 presents the validation results for the mortality function.

The growth and mortality empirical expressions satisfy the general analytical conditions regarding functions in system $(\mathrm{H})$ for $(x, \bar{N}) \in$ $\left[x_{0}, \omega\right] \times[K,+\infty)$, in which $K$ is a sufficiently small real value such that $K / A>1$. The numbers prevailing in commercial culture are restricted to well within this domain.

The price function. Pricing information of fresh whole shrimp (August and September 2008) was supplied by a local seafood distributor, operating in the Yucatan Peninsula. The individuals harvested are commercialized by size and their price depends on the number of individuals which can be packed per unit of weight. By a simple arithmetical calculation, a size-price relation can be obtained. Table A2 
TABLE A2. Shrimp price in $\$$ US in Yucatan ( $\omega$ represents the maximum shrimp size)

\begin{tabular}{lc}
$\begin{array}{l}\text { Rank of size } \\
(\mathrm{g})\end{array}$ & $\begin{array}{l}\text { Price }^{\mathrm{a}} \\
(\$ \mathrm{US} / \mathrm{g})\end{array}$ \\
\hline$(0,6.6)$ & 0.0061 \\
{$[6.6,7.7)$} & 0.0063 \\
{$[7.7,9.2)$} & 0.0066 \\
{$[9.2,11.5)$} & 0.0077 \\
{$[11.5,13.1)$} & 0.0082 \\
{$[13.1,15.3)$} & 0.0085 \\
{$[15.3,18.3)$} & 0.0087 \\
{$[18.3,22.7)$} & 0.0088 \\
{$[22.7,32.1)$} & 0.0089 \\
{$[32.1, \omega)$} & 0.009
\end{tabular}

${ }^{\text {a }}$ Prices from a local distributor of seafood, operating in Yucatan Peninsula.

includes the different ranks of size and price in \$US for the commercialized product in Yucatan.

As can be observed in Table A2, the price-size relation follows a nondecreasing piecewise function. In order to use a differentiable function in the model, a logistic price function was fitted to the mean value in every size interval in Table A2. The resulting nonlinear least squares estimation problem was implemented in Software InfoStat/Professional 1.1 and solved by using the Levenberg-Marquardt iterative method. Table 2 shows the parameters estimated, which were statistically positive with a probability higher than 0.99 .

It is feasible to use the piecewise function shown in Table A2 directly to estimate the optimal harvesting time. To do so, the optimization method described in Section 4 can be extended by considering the extreme of each size interval as a possible local maximum of the problem. The optimal harvesting times were calculated using the piecewise function, and the results obtained indicate that the general conclusions are not substantially affected when this price function is considered. Due 
to the large number of steps in the price-size relation in Table A2, the continuous logistic function can be considered a good approximation of the data. In order to simplify the analytical treatment of the problem, the results with the piecewise price function are omitted.

\section{REFERENCES}

A.S. Ackleh, K. Deng, and X. Wang [2004], Competitive Exclusion and Coexistence for a Quasilinear Size-Structured Population Model, Math. Biosci. 192, 177-192.

O. Angulo, and J.C. López-Marcos [1999], Numerical Schemes for Size-Structured Population Equations, Math. Biosci. 157, 169-188.

O. Angulo, and J.C. López-Marcos [2004], Numerical Integration of Fully Nonlinear Size-Structured Population Models, Appl. Numer. Anal. 50, 291-327.

S.J. Arnold, M.J. Sellars, P.J. Crocos, and G.J. Coman [2006], An Evaluation of Stocking Density on the Intensive Production of Juvenile Brown Tiger Shrimp (Penaeus esculentus), Aquaculture. 256, 174-179.

M.E. Araneda [2010], Análisis de la producción intensiva del camarón blanco Penaeus vannamei en agua dulce: un enfoque bioeconómico. Ph.D. Thesis, Centro de Investigación y de Estudios Avanzados del Politécnico Nacional, Unidad Mérida, Yucatan, Mexico.

M.E. Araneda, E.P. Pérez, and E. Gasca-Leyva [2008], White Shrimp Penaeus Vannamei Culture in Freshwater at Three Densities: Condition State Based on Length and Weight, Aquaculture. 283, 13-18.

R. Arnason [1992], Optimal Feeding Schedules and Harvesting Time in Aquaculture, Mar. Res. Econ. 7, 15-35.

J.M. Barbosa, S.S. Brugiolo, J. Carolsfeld, and S.S. Leitão [2006], Heterogeneous Growth in Fingerlings of the Nile Tilapia Oreochromis Niloticus: Effects of Density and Initial Size Variability, Braz. J. Biol. 66, 537-541.

T. Bjørndal [1988], Optimal Harvesting of Farmed Fish, Mar. Res. Econ. 5, $139-159$.

J.R. Brett [1979], Enviromental Factors and Growth, in Fish Physiology, vol 8, p. 599-667, (W.S. Hoar, D.J. Randall, D.J. and J.R. Brett, Eds.), Academic Press, London.

A. Calsina, and J. Saldaña [1995], A Model of Physiological Structured Population Dynamics with a Nonlinear Individual Growth Rate, J. Math. Biol. 33, 335-364.

C.W. Clark [1990], Mathematical Bioeconomics. The Optimal Management of Renewable Resources, John Wiley \& Sons, New York.

J.E. Colt, and G. Tchobanoglous [1981], Design of Operation Systems for Aquaculture, in (L.J. Allen and E. Kinney, eds.)Proceedings of the Bio-Engineering Symposium for Fish Culture, pp. 138-148, American Fisheries Society, Bethesda, MD.

O.I. Forsberg [1996], Optimal Stocking and Harvesting of Size-Structured Farmed Fish: A Multi-Period Linear Programming Approach, Math. Comput. Simulat. 42, 299-305. 
O.I. Forsberg [1999], Optimal Harvesting of Farmed Atlantic Salmon at Two Cohort Management Strategies and Different Harvest Operation Restrictions, Aq. Econ. Manag. 3, 143-158.

S. Gadagkar [1997], Social Behaviour and Growth Rate Variation in Cultivated Tilapia (Oreochromis niloticus), Ph.D. Thesis, Dalhousie University Halifax, Nova Scotia.

E. Gasca-Leyva, J.M. Hernandez, and V.M. Veliov [2008], Optimal Harvesting Time in Size-Heterogeneous Population, Ecol. Model. 210, 161-168

S.C. Gurney, G. Tyldesley, S.N. Wood, P.J. Bacon, M.R. Heath, A. Youngson, and A. Ibbotson [2007], Modelling Length-At-Age Variability Under Irreversible Growth, Can. J. Fish. Sci. 64, 638-653.

N. Harán, J. Mallo, and J. Fenucci [2004], Density Influence on Growth and Development of the Petasma in Juvenile Shrimps Pleocticus Muelleri (Decapada, Penaeoidea), Invest Mar. 32, 11-18.

R.L. Hean [1994], An Optimal Management Model for Intensive Aquaculture An Application in Atlantic Salmon, Australian J. Agr. Econ. 38, 31-47.

T. Heaps [1995], Density Dependent Growth and the Culling of Farmed Fish, Mar. Res. Econ. 10, 285-298.

J.M. Hernández, M. León-Santana, and C.J. León [2007], The Role of the Water Temperature in the Optimal Management of Marine Aquaculture, Eur. J. Oper. Res. 181, 872-886.

B.R. Howell [1998], The Effect of Stocking Density on Growth and Size Variation in Cultured Turbot and Sole, ICES CM 1998/L:10.

J.E. Huguenin, and J. Colt [2002], Design and Operating Guide for Aquaculture Seawater Systems, 2nd edn., Elsevier Science, Amsterdam.

M. Huss, L. Persson, and P. Byström [2007], The Origin and Development of Individual Size Variation in Early Pelagic Stages of Fish, Oecologia. 153, 57-67.

N. Kato, S. Oharu, and K. Shitaoka [2007], Size-Structured Plant Population Models and Harvesting Problems, J. Comput. App. Math. 204, 114-123.

P. Kestemont, E. Baras, S. Jourdan, M. Houbarta, Ch. Melard, M. Paspatis, P. Fontaine, A. Cuviera, M. Kentouri, and E. Baras [2003], Size Heterogeneity, Cannibalism and Competition in Cultured Predatory Fish Larvae: Biotic and Abiotic Influences, Aquaculture. 227, 333-356.

H. Kjartansson, F. Sveinung, J.M. Tomasen, and M.J. Smith [1988], Effects of Different Stocking on Physiological Parameters and Growth of Adult Atlantic Salmon (Salmon Salar L.) Reared in Circular Tanks, Aquaculture. 73, 261-274.

T. Kostova [2002], An Explicit Third-Order Numerical Method for SizeStructured Population Equations, Numer. Methods Partial. Diff. Eq. 19, 1-21.

T. Lawson [1995], Fundamentals of Aquaculture, Chapman and Hall, MA.

M. Léon-Santana, and J.M., Hernández [2008], Optimum Management and Environmental Protection in the Aquaculture Industry, Ecol. Econ. 64, 849-857.

K. Lorenzen [1996], A Simple von Bertalanffy Model for Density-Dependent Growth in Extensive Aquaculture, with an Application to Common Carp (Cyprinus carpio), Aquaculture. 142, 191-205. 
T. Lorenzen [2008], Modeling Climate Change and the Effect on the Norwegian Salmon Farming Industry, Nat. Res. Model. 21, 416-435.

J.A. Mistiaen, and I. Strand [1999], Optimal Feeding and Harvest Time for Fish with Weight-Dependent Prices, Mar. Res. Econ. 13, 231-246.

D. Moran [2007], Size Heterogeneity, Growth Potential and Aggression in Juvenile Yellowtail Kingfish (Seriola lalandi Valenciennes) Aquac. Res. 38, 1254-1264.

E. Moxnes [2005], Policy Sensitivity Analysis: Simple Versus Complex Fishery Models, Syst. Dyn. Rev. 21, 123-145.

S.D. Peacor, R.J. Bence, and C.A. Pfister [2007 ${ }^{\mathrm{a}}$, The Effect of Size-Dependent Growth and Environmental Factors on Animal Size Variability, Theor. Popul. Biol. 71, 80-94.

S.D. Peacor, and C.A. Pfister [2006], Experimental and Model Analyses of the Effects of Competition on Individual Size Variation in Wood Frog (Rana sylvatica) Tadpoles, J. Anim. Ecol. 75, 990-999.

S.D. Peacor, L. Shiesari, and E.E. Werner $\left[2007^{\mathrm{b}}\right]$, Mechanisms of Nonlethal Predator Effect on Cohort Size Variation: Ecological and Evolutionary Implications, Ecology. 88, 1536-1547.

C.A. Pfister, and S.D. Peacor [2003], Variable Performance of Individuals: The Role of Population Density and Endogenously Formed Landscape Heterogeneity, J. Anim. Ecol. 72, 235-725.

B. Posadas, and T. Hanson [2006], Economics of Integrating Nursery Systems into Indoor Biosecure Recirculating Saltwater Shrimp Grow-Out Systems, in Shrimp Culture: Economics, Market, and Trade, (P-S. Leung and C. Engle, eds.), pp. 279-289, Blackwell Publishing, IO.

R.S. Pindyck, and D.L. Rubinfeld [1981], Econometric Models and Economic Forecast, McGraw-Hill, New York.

W.J. Reed, and H.R. Clarke [1990], Harvest Decisions and Asset Valuation for Biological Resources Exhibiting Size-Dependent Stochastic Growth, Int. Econ. Rev. 31, 147-169.

J.W. Sinko, and W. Streifer [1967], A New Model for Age-Size Structure of a Population, Ecology. 48, 910-918.

S.T. Summerfelt, J.A. Hankins, S.R. Summerfelt, and J.M. Heinen [1993], Modeling Continuous Culture with Periodic Stocking and Selective Harvesting to Measure the Effect on Productivity and Biomass Capacity to Fish Culture Systems, in Techniques for Modern Aquaculture, (J.K. Wang, ed.), Proceedings of the Aquacultural Engineering Conference, Spokane, Washington, 21-23 June, pp. 581-595.

O. Tahvonen [2008], Harvesting an Age-Structured Population as Biomass: Does it Work? Nat. Res. Model. 21, 525-550.

O. Tahvonen [2009], Optimal Harvesting of Age-Structured Fish Populations, Mar. Res. Econ. 24, 147-169.

P. Van Wyk, M. Davis-Hodgkins, C.R. Laramore, K.L. Main, J. Mountain, and J. Scarpa [1999], Farming Marine Shrimp in Recirculating Freshwater Systems, FDACS Contract M520. Florida Department of Agriculture and Consumer Services, Tallahassee, FL. 
OPTIMAL HARVESTING TIME FARMED AQUATIC POP. 513

V. Veliov [2008], Optimal Control of Heterogeneous Systems: Basic Theory, J. Math. Anal. Appl. 346, 227-242.

G.L. Volpato, and M.O. Fernandes [1994], Social Control of Growth in Fish, Braz. J. Med. Biol. Res. 27, 797-810.

R. Yu, and P-S. Leung [2005], Optimal Harvesting Strategies for a Multi-Cycle and Multi-Pond Shrimp Operation: A Practical Network Model. Math. Comput. Simulat. 68, 339-354. 